\section{Summary points}

Collaboration between public health and veterinary services could increase coverage of essential health interventions for people and livestock in remote rural areas

Such collaboration has been rare and outcomes rarely assessed

Joint vaccination campaigns for livestock and people among nomadic pastoralists of Chad were successful and highly appreciated by stakeholders

Communication between the public health and veterinary programmes must be fostered to identify further opportunities for collaboration

Ethical approval: The joint vaccination campaigns in Chad were approved by the Ministry of Health and the Ministry of Livestock Production. A review board comprising officials of the ministries, reviewed the compliance with ethical standards. Participation was voluntary and the communities were informed of the possible side effects of vaccination.

Livestock in Development. Livestock in poverty-focused development. Somerset: $\mathrm{LiD}, 1999$.

2 Thornton PK, Kruska RL, Henninger N, Kristjanson PM, Reid RS, Atieno $\mathrm{F}$, et al. Mapping poverty and livestock in the developing world. Nairobi: International Livestock Research Institute, 2002.
3 Cheneau Y, El Idrissi AH, Ward D. An assessment of the strengths and weaknesses of current veterinary systems in the developing world. Rev Sci Tech 2004:23:351-9.

4 Wyss K, Moto DM, Callewaert B. Constraints to scaling-up health related interventions: the case of Chad, Central Africa.J Int Dev 2003;15:87-100. Majok AA, Schwabe CW. Development among Africa's migratory pastoralists. Westport: Greenwood Publishing, 1996.

6 Meslin FX. Global changes: perspectives on future roles of veterinarians in public health. Vol 1. Feldafing, Deutsche Stiftung für Internationale Entwicklung - Zentralstelle für Ernährung und Landwirtschaft, 1996:101.

7 Ward DE, Ruppaner R, Marchot PJ, Hansen JW. One medicine-practical application for non-sedentary pastoral populations. Nomadic Peoples 1993:32:55-63.

8 Jamison DT, Mosley WH, Measham AR, Bobadilla JL. Disease control: priorities in developing countries. New York: Oxford University Press, 1993.

9 Schwabe C. Veterinary medicine and human health. Baltimore: Williams and Wilkins, 1984

10 Roth F, Zinsstag J, Orkhon D, Chimed-Ochir C, Hutton GCO, Carrin G, et al. Human health benefits from livestock vaccination for brucellosis: case study. Bull World Health Organ 2003;81:867-76.

11 Bonfiglioli AM, Watson C. Unicef/UNSO project for nomadic pastoralists in Africa (NOPA). New York: UNICEF, 1992.

12 Niamir-Fuller M. Managing mobility in African rangelands: the legitimization of transhumance. London: Impressum, Food and Agriculture Organization of the United Nations, 1999

13 Hampshire K. Networks of nomads: negotiating access to health resources among pastoralist women in Chad. Soc Sci Med 2002;54:1025-37.

14 Hill AG,,Randall S. Différences géographiques et sociales dans la mortalité infantile et juvénile au Mali. Population 1984;6:921-46.

15 Schelling E, Daoud S, Daugla DM, Diallo P, Tanner M, Zinsstag J. Morbidity and nutrition patterns of three nomadic pastoralist communities of Chad. Acta Trop 2005;95(1):16-25.

16 Daoud S, Yam A, Daugla DM, Schelling E, Diguimbaye C, Bidjeh K, et al. Couverture vaccinale et prévalence des affectations courantes chez les nomades du Chari-Baguirmi et du Kanem au Tchad. Sempervira 2000;8:37-43

17 Bechir M, Schelling E, Wyss K, Daugla DM, Daoud S, Tanner M, et al. An innovative approach combining human and animal vaccination campaigns in nomadic settings of Chad: experiences and costs. Med Tropcampaigns in nomadic sars) 2004;64:497-502
(Mars

18 Zinsstag J, Schelling E, Wyss K, Bechir M. Potential of cooperation between human and animal health to strengthen health systems. Lancet (in press)

19 Shears P. Communicable disease surveillance with limited resources: the scope to link human and veterinary programmes. Acta Trop 2000;76:3-7.

20 Forget G, Lebel J. An ecosystem approach to human health. Int J Occup Environ Health 2001;7:3-36.

\title{
Why shouldn't children benefit from oral rehydration solutions for calves?
}

When I was a veterinary student, in the early 1960s, diarrhoea was regarded entirely as an infection; antibiotics were the automatic remedy. During my final year, an exciting innovation was intravenous fluid therapy for calves with acute diarrhoea. Too expensive for widespread use, it never matched the success of similar treatment for human cholera, yet the practical problems of treating calf diarrhoea on farms were not much different from those of treating cholera in primitive surroundings. Indeed, as well as the general similarities in the pathophysiology of acute diarrhoea in any species, the then prevalent cause of calf diarrhoea, Escherichia coli enterotoxin, and cholera are similar.

Oral rehydration for acute diarrhoea was first suggested by remarkable clinical research by W B O'Shaughnessy reported in the Lancet in 1831, within months of the arrival of a terrifying new disease from Asia-cholera. Sadly his wisdom was not appreciated until the 1970 s, with the arrival of the World Health Organization's oral rehydration solution-described as the greatest lifesaving advance of the century. It converted cholera from a mostly fatal disease in the absence of intravenous rehydration, into one routinely and simply treated orally. Oral rehydration goes beyond symptomatic therapy; the fundamental cause of acute diarrhoea is impairment of net enteric sodium and water absorption sufficient to overwhelm the compensatory capacity of the colon.

Veterinary oral rehydration solutions initially followed human formulations, but there are now three classes: type 1 solution (WHO formulation) corrects dehydration, hypovolaemia, and acidosis; type 2 solutions have the properties of type 1 solutions but avoid the energy deficits imposed by their low glucose content (2\%), which is optimal for sodium absorption but inadequate for metabolism; and type 3 solution, which exploits the ability of glutamine to sustain villus structure and enterocyte function, and renal function, and can be helpful in conditions where reduced food intake imperils villus architecture.

Principles validated in calves may not necessarily apply to children, but we should not simply assume that they won't. Calves are pre-ruminants; they are functionally simple-stomached until they are weaned onto solid food, well beyond the age at which oral rehydration is usually needed. Unlike children, calves can be studied in the laboratory to measure directly the parameters that matter in acute diarrhoea-such as hypovolaemia, acidosis, and prerenal failure.

Paediatric research is necessarily restricted to indirect and fallible criteria such as faecal output or need for supplementary intravenous fluids; the dilemma for studies of human oral rehydration therapy is that the validity of systematic reviews and meta-analyses is undermined when the underlying data reflect crucial variables only indirectly and unreliably. It is therefore possible that the approaches currently used to treat calves, which are radically different from those used by paediatricians, could benefit children, especially those who are already cachectic before their diarrhoea. The necessary additional research should be started.

Bob Michell professor of comparative medicine, Barts and The London School of Medicine and Dentistry,John Vane Science Centre, London (bobmichell@hotmail.com) 